CIUDAD Y TERRITORIO

ESTUDIOS TERRITORIALES

ISSN(P): $1133-4762$; ISSN(E): 2659-3254

Vol. LIII, № 209 , otoño 2021

Págs. 685-700

https://doi.org/10.37230/CyTET.2021.209.05

CC BY-NC-ND

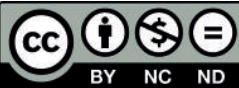

\title{
La "metropolitanización" del turismo: el caso del Área Metropolitana de Barcelona
}

\author{
Montserrat CRESPI-VALLBONA.
}

\begin{abstract}
Resumen: El auge del fenómeno turístico en la ciudad de Barcelona tiene su impulso en los Juegos Olímpicos de 1992. En ese momento, se sitúa en el mapa de los visitantes potenciales como destino de interés, y la cifra de turistas internacionales se incrementa año tras año. Tal volumen de población flotante se convierte en una prioridad para la administración local, siendo objeto de debate en los planes de actuación municipal. En un primer momento, para promocionar y atraer el interés hacia la ciudad, y así desarrollarla turísticamente. A partir de los Planes Estratégicos de 2015 y 2020, el objetivo principal es limitar la turistificación entre otros impactos negativos, y buscar la manera de conciliar la estancia de los visitantes con la vida cotidiana de los residentes. Puesto que una de las características del turismo es la difusión de sus efectos en el entorno inmediato, el objeto de este estudio es analizar la repercusión que la actividad turística de un destino consolidado como Barcelona tiene en su área urbana funcional, concretamente en el denominado AMB (Área Metropolitana de Barcelona).
\end{abstract}

Palabras clave: Área Metropolitana de Barcelona (AMB); Turismo sostenible;Plan estratégico; Vivienda turística.

\section{Tourism metropolitanization: the case of the Metropolitan Area of Barcelona}

Abstract: The rise of the tourist phenomenon in the city of Barcelona had its momentum in the 1992 Olympic Games. At that time, the city was placed on the map of potential visitors as a destination of

Recibido: 10.06.2020; Revisado: 04.12.2020

Correo electrónico: mcrespi@ub.edu ; № ORCID: https://orcid.org/0000-0001-8267-4786

La autora agradece los comentarios y sugerencias realizados por los evaluadores anónimos, que han contribuido a mejorar y enriquecer el manuscrito original

Esta investigación ha sido financiada por el Proyecto I+D Nuevas movilidades y reconfiguracion sociorresidencial en la poscrisis: consecuencias socioeconomicas y demograficas en las areas urbanas españolas (RTI2018-095667-B-I00), siendo la Dra. Cristina López y el Dr. Fernando Gil-Alonso sus investigadores principales. 
interest, and since then the number of international tourists has increased, year after year. Such a volume of temporary population also becomes a priority for the local administration, being a subject of debate in the city's municipal action plans. At first, to promote and attract interest in the city, and thus to develop it touristically. However, from the Strategic Plans of 2015 and 2020, the main objective is to limit touristification among other negative impacts, and to find a way to reconcile the temporality of visitors with the daily life of residents. Since one of the characteristics of tourism is that its effects expand on the immediate environment, the purpose of this study is to analyze the impact that the tourism activity of a consolidated destination as Barcelona has in its urban functional area, specifically in the so-called AMB (Metropolitan Area of Barcelona).

Key words: Metropolitan Area of Barcelona (AMB); Sustainable tourism; Strategic plan; Tourist housing.

\section{Introducción}

B arcelona es un destino turístico mundial. Las cifras lo avalan: cerca de 18 millones de turistas anuales, ciento cincuenta mil visitantes de media al día, casi cincuenta millones de pasajeros en el aeropuerto de Barcelona-El Prat, tres millones de cruceristas, más de ciento cuarenta mil plazas de alojamiento turístico reglado. Los visitantes significan, pues, unos ingresos notables para la ciudad y el turismo se convierte en un negocio rentable (representando el 10\% del PIB según datos de Turismo de Barcelona, 2019). Su impacto en la ciudad trasciende la de una actividad meramente complementaria, para situarse en el centro de su estructura económica, marcando su cotidianedad y su vida comunitaria (Vera \& al., 1997; Antón Clavé, 1998; López Palomeque, 2015).

Barcelona refleja como el turismo deviene el mayor motor de impulso económico para un destino (BUTLER, 1980), hasta que éste se consolida y satura llegando a su límite de atracción, de capacidad de carga máxima y a protagonizar efectos perversos. Sin abandonar el aspecto económico, el turismo implica el desarrollo y potenciación de ciertos sectores y, también, el deterioro y olvido de otros, como ya se señalaba en los inicios de los análisis académicos en torno al turismo y sus efectos (GreENWOod, 1972). Así, destacan impactos negativos como: turistificación (JANSEN-VERBEKE, 1998), ludificación (BAPTISTA, 2005), patrimonialización (Almirón, 2004; Prats, 2004; Bertoncello \& al., 2003), banalización y/o disneyfication (ZukIN, 1995; Prats, 2009), efecto expulsión (Goldstone, 2003), overtourism o masificación del espacio urbano (PeETers \& al., 2018; Font \& al., 2019; MıLANo, 2018), turismofobia o resistencias sociales (Huete \& MANTECón, 2018; MANSILLA, 2018). En definitiva, el turismo supone todo un reto y desafío para las organizaciones que gestionan los destinos (Colomb \& Novy, 2016), y más aún con la necesidad y compromiso de una gobernanza responsable, ética y sostenible (IVARS-BAIDAL \& al., 2017; CRESPIVallbona \& Mascarilla-Miró, 2018; Koens \& al., 2018; ECKERT \& al., 2019).

Cuando los límites geográficos y administrativos de las ciudades trascienden en áreas urbanas funcionales (FERIA TORIBIO, 2004), estos procesos y transformaciones turísticas también pueden llegar a incurrir a escala metropolitana, puesto que el futuro de los destinos turísticos consolidados tiene su razón de ser en su geografía inmediata (BARRADO, 2010; MANTERO, 2010). En pro de este desarrollo turístico, se recurre a implementar distintas estrategias orientadas a definir un lugar atractivo y acorde a las potenciales demandas turísticas, para lo cual el pasado patrimonial y testimonial, junto con la cultura local y los atributos naturales se convierten en fuentes o materias primas con las que se llevan adelante estrategias de acondicionamiento, escenificación, tematización y patrimonialización que dan como resultado una región metropolitana con una alta capacidad para atraer turistas (BERTONCELlo \& Luso, 2016). Para que la expansión de los beneficios del turismo en el área metropolitana sea efectiva y que su desarrollo sea sostenible se precisa de la colaboración estratégica de los diferentes stakeholders del territorio (RICHARDS, 2010)

En este sentido, el objetivo de este artículo es analizar los efectos y transformaciones de una metrópolis turística consolidada en su área urbana funcional, esto es qué características, ritmos y magnitudes presenta la "turistificación" en el Área Metropolitana de Barcelona (AMB). Barcelona es un destino de primer orden mundial, por lo que el análisis de su área urbana funcional permite dilucidar luces y sombras ante los procesos de "metropolitanización" del turismo. El estudio pretende analizar los 
impactos del turismo en el AMB en cuanto a su oferta de alojamiento reglado, específicamente de la vivienda de uso turístico; estudiar la dimensión y la base del relato de la marca turística metropolitana; y por último, profundizar en el ente responsable de la gobernanza turística metropolitana y en sus acciones desempeñadas y de futuro.

Metodológicamente, este artículo tiene un carácter descriptivo, recurriendo al análisis de datos secundarios de documentos e informes gubernamentales en torno a la gestión del AMB, así como de sus web de promoción y producción de productos turísticos.

\section{El turismo urbano y su expansión en el área territorial funcional}

El turismo no se desarrolla aisladamente en un enclave específico y separado, sino que participa de la vida social, económica y cotidiana de los destinos, lo que para OBRADOR-PONS \& al. (2009:10) supone un juego contínuo de circulación y movilidad, de "desterritorialización y reterritorialización”. Los territorios desde su conformación son un entramado de intercambios y relaciones, es decir, atienden a procesos y dinámicas construidos e imaginados, percibidos, establecidos, apropiados, vividos y cuestionados (GUPTA \& FERGUSON, 1992). Es precisamente este carácter multidimensional y temporal del turismo, esta concepción relacional del espacio (MASSEY, 2005) lo que permite considerar que el alcance de la ciudad o la metrópolis y su área urbana funcional también deviene turística. Esto es, que el turismo no es un fenómeno segregado del sistema metropolitano, del mismo modo que el territorio no es ajeno a la actividad turística (ARIAS SANS, 2019). De ello, se desprende el turismo metropolitano o "metropolitanización" del turismo.

No obstante, la "metropolitanización" del turismo, es decir, la expansión de la actividad turística desde su centralidad a su hinterland o área urbana funcional precisa el acondicionamiento del lugar, la escenificación del paisaje para su desarrollo. Es decir, se debe adecuar el destino a los requerimientos turísticos, esto es, crear relato, crear vocación turística (BERTONCELLo \& Luso, 2016).

El desarrollo del turismo urbano se ha enfocado en el análisis de sus áreas centrales o históricas, ávidas de patrimonio tangible arquitectónico y artístico, desatendiendo, habitualmente su pasado fabril o industrial (CAPEL, 2005). Poner en valor el patrimonio se convierte en la base del desarrollo turístico urbano (CHOAY, 2000; HARVEY, 2002; Bertoncello \& al., 2003). En este sentido, la patrimonialización supone no solo destacar la relevancia del patrimonio tangible e intangible de un territtorio, sinó la creación de una conciencia patrimonial entre su comunidad, un sentimiento de apego y pertenencia por el lugar (Bertoncello, 2002). Otra de las estrategias de valorización de los lugares para su despegue turístico es la tematización, como resultado de una narrativa específica en torno a un tema (un hecho histórico o un aspecto propio de la cultura local) en el que se despliegan distintos puntos de interés en el territorio. Ello permite crear asociaciones entre estos distintos enclaves, convocando la curiosidad del turista para conocerlo y descubrirlo (BOYER, 2004; GOTHAM, 2002). LOS remanentes patrimoniales son la base material para el desarrollo del relato temático, aunque también se puede recurrir a la réplica, la recreación e inclusive la ficción. El ejemplo paradigmático de este último son los parques temáticos (COHEN, 2005). En cualquier caso, la tematización es también una estrategia privilegiada, principalmente cuando un destino no tiene atractivos individuales con suficiente potencial y singularidad para convertir el lugar en destino de obligada visita. La tematización confiere cuerpo y relevancia en su conjunto, y permite un desarrollo más disperso territorialmente y a la vez, más sinérgico. Permite una expansión desde un centro hacia su hinterland, siguiendo el modelo de Mıossec (1977).

Ambas estrategias, la patrimonialización y la tematización son las herramientas más recurrentes en los procesos de "turistificación", pues permiten organizar productos como excursiones o visitas guiadas, entre otros, que facilitan su conocimiento, disfrute y comercialización. Es decir, estos marcos simbólicos y referenciales identitarios que definen la personalidad del lugar se convierten en atractivos de reclamo cognitivo y hedónico para su ciudadanía. También se convierten en reclamo turístico, esto es, transitan a su "turistificación". Con ellos, se persigue embellecer y adecuar paisajisticamente el lugar para hacerlo apetecible turísticamente (CRANG, 1999; DunCAN \& DUNCAN, 2001; MitCHELL, 2003; LÜBBREN \& $\mathrm{CROUCH}_{\mathrm{r}}$ 2003), seleccionando aquellas imágenes materiales o inmateriales que el consumidor quiere ver e induciéndolo a ver aquello que espera y, el destino ha construido para su admiración (MACCANNEL, 2003). Este relato turístico puede basarse también en el paisaje pictórico, desarrollando un "artscape" como pool de atracción (GALOFARO, 2003). El street art sería un buen ejemplo de ello (BEST, 2012; CRESPIVALLBONA \& MASCARILLA-MIRÓ, 2020). 
En cualquier caso, la promoción turística es el instrumento utilizado para proyectar la imagen de aquella realidad que se construye para atraer visitantes. La imagen que se proyecta al exterior para su consumo turístico, la creación del relato que se promociona, puede no tener demasiado que ver con la estructura y dimensión del lugar, puesto que se diseña pensando en la alteridad, más que en la propia identidad local (PALOU, 2019). En este sentido, si bien el paisaje patrimonial de una ciudad es construido a raíz de su historia social (Delgado, 2004; ANTICH, 2013), el interés turístico interviene alterándolo física y simbólicamente (ChAUDEFAUD, 1987), puesto que este consumidor necesita marcadores singulares, únicos y destacados (MacCANNEL, 2003). En definitiva, el patrimonio por si mismo no contiene identidad, pero permite la creación de una idea de identidad, jerarquizando y visibilizando unos determinados iconos en detrimiento de otros, y a merced de unas ideologias e intereses políticos concretos (PALOU, 2019). Por tanto, también altera las percepciones, afecciones y desafecciones de su población. Sin duda, altera social y materialmente los lugares. Ello es irreversible y debe ser asumido, pues genera disputas, conflictos o cambios en las relaciones sociales, económicas y culturales de dicho lugar (LÓPEz LóPEz, 2016).

Por otro lado, desde la óptica de los consumidores de turismo urbano y cultural, éstos codician aquellos destinos que destacan la singularidad específica del lugar y les permiten conexiones e interacciones sociales, a través de estilos de vida cosmopolitas y sensibilidades cultivadas relacionadas con la cultura (Stebbins, 1997; MILES, 2007), gastronomía y espacios gourmet (CRESPI-VALLBONA \& Dimitrovski, 2016), estilos musicales, compras en tiendas vintage, consumo de cervezas artesanales, etc. (BRIDGE \& DoWLING, 2001; ZUKIN, 2008; ERNST \& Doucet, 2014), creando un comportamiento consumista y un estilo de vida propio de los centros turísticos glamourizados y estetizados, creando clusters de servicios que constituyen escenas de consumo especializados para estos consumidores culturales (SILVER \& CLARK, 2016). Junto a ellos, proliferan también aquellos consumidores que reclaman otras experiencias, silenciadas, anuladas de los discursos oficiales (RuBIO-ARDANZ, 2014). Esto es, apartadas de los centros "turistificados", siendo áreas ordinarias, sin glamour o interés turistico oficial.

La "metropolitanización" del turismo puede absorber ambas tendencias de consumidores turísticos. El espacio metropolitano de flujos turísticos manifiesta la dualidad de lo global y cosmopolita versus lo local; de los cambios y la innovación en contraposición a la persistencia y la tradición. Estas tensiones y contradicciones son presentes en las tendencias actuales de la demanda turística: un contexto global pero reclamando la experiencia de lo local (HANneRz, 1989; SALAZAR, 2005), espacios cotidianos de vida con fragmentos de socialidad y sociabilidad (DELGADo RuIz, 1999). Para Simmel (1903), las metrópolis son lugares de hiperestimulación o de flâneur, en los que abundan los no-lugares d'Augé, burbujas de inmanencia, espacios de vida mundanos y ordinarios, de vecindario, de comunidad trabajadora (MAITLAND \& NEWMAN, 2009; StORS \& KagermeiJer, 2013; Füller \& Michel, 2014; Mordue, 2017; Gravari-Barbasa \& al. 2017; FRISCH \& al., 2019). Tanto los turistas recurrentes como los ocasionales centran su interés en estas experiencias vivenciales -incluyentes e inclusivas-, asumiendo tanto los itinerarios institucionalizados o apropiados como los más novedosos puestos en escena para ser resignificados turísticamente. El turista metropolitano busca ir más allá del espacio que define la urbe. Busca la convivencia, las gentes que la habitan y la transitan, la cotidianeidad de lo usual y la irrupción de lo inusual, la interacción de la identidad y la alteridad. Busca el trueque, no solo de mercancias, sino también de palabras, deseos, recuerdos (CALVINO, 1988).

En este sentido, la "metropolitanización" del turismo permite abordar las características y transformaciones de las áreas periféricas tradicionales, alejándolas del rol pasivo y secundario, de meras ciudades dormitorio, marginadas o pauperizadas sin historia ni proyectos propios. La "metropolitanización" del turismo augura un rol activo, una presencia viva y relevante, no solo funcional, sino cultural y económica de los municipios que configuran las áreas metropolitanas. Solo precisa escenificar, tematizar, recrear los paisajes visuales, materiales, pictóricos, embellecidos, que trascienden el turismo urbano para escalar al turismo metropolitano, pero con sello propio, ofreciendo alternativas de dimensión local dentro del escenario global. Consecuentemente, se precisa crear identidad, sentimiento de pertenencia, apego y comunidad. La identidad confiere al espacio entidad de territorio, es expresión de la dimensión cultural que se acredita en el patrimonio y el testimonio material e inmaterial, conformando recursos endógenos, paisajes, escenarios de actividad turística para impulsar el desarrollo sostenible para atraer y promover. Algunos ejemplos estudiados de 
"metropolitanización" del turismo son el caso de Madrid (BARRADO, 2010), Buenos Aires (Bertoncello \& Luso, 2016) o las metrópolis asiáticas de Sydney, Tokyo, Kuala Lumpur and Seoul, entre otras (RICHARDS, 2010).

\section{Gobernanza y sostenibilidad del turismo}

El turismo es inherente al fenómeno urbano actual. Condiciona y estructura su día a día económica, social y culturalmente con sus infraestructuras, su tejido productivo, su consumo y sus imágenes, transformando constantemente física y conceptualmente la ciudad (SHELLER \& URRY, 2004). El espacio urbano no solo es compartido entre residentes y turistas, sino que además es resignificado, reconstruido a partir de sus ambas dinámicas. Y por ello, estos espacios urbanos "asumen roles" interdependientes de movilidad y usos (civiles, festivos, culturales, laborales, comerciales) según sean sus usuarios: residentes, turistas o trabajadores (BASSAND \& JOYE, 2001). Los residentes son los que más sufren la saturación debido al deterioro de su calidad de vida, la contaminación acústica, la falta de plazas de aparcamiento, la falta de viviendas para comprar o alquilar. Como señalan CResPi-VALLBONA y Domínguez-PéRez (2021), la gentrificación y a la transformación de la vivienda para propósitos turísticos y comerciales en plataformas de alojamiento colaborativo, como Airbnb, fenómeno conocido como airbnbification (RICHARDS, 2016), son fenómenos reiterados en los destinos turísticos actuales. Este es el efecto expulsión (crowding out) que la actividad turística provoca sobre el resto de la estructura económica, social y urbana; implica una expulsión física y simbólica de los pobladores de los espacios revitalizados (SASSEN, 2014) y una tensión entre el uso de la vivienda para usos residenciales ante los usos temporales-turísticos, lo que se conoce como gentrificación turística (ARIAS SANS, 2018; Cócola-GANT, 2018; Domínguez-PÉrez \& al., 2021).

La "turistificación" intensifica la funcionalidad de la ciudad como lugar de mercadeo, como producto de uso y consumo (ZUKIN, 2008), cambiando las actividades económicas locales tradicionales (SENGEL \& al., 2015), centrándose en la gastronomía, el ocio y las actividades culturales, conllevando a una desvitalizacion del vecindario. La "turistificación" comporta la expulsión o gentrificación comercial (GONZÁLEZ \& WALEY,
2012) del comercio tradicional de productos básicos y cotidianos, o la orientación de determinadas inversiones en el ámbito de la cultura y la movilidad.

Tales transformaciones han conllevado la reacción y exasperación de los ciudadanos en muchas ciudades maduras y consolidadas turísticamente, reclamando la atención mediática para difundir con más eco su malestar. Overtourism es la palabra que describe la gestión de la congestión y el exceso de carga de capacidad turística de los destinos (UNWTO, 2018). Muchos son los académicos que han analizado esta saturación de afluencia de visitantes en determinados enclaves turísticos (LAZZAROTTI, 1994; SAARINEN, 2006; Peeters \& al., 2018; Font \& al., 2019; Milano, 2018), Paralelamente, se ha desencadenado una reacción contraria, "turismofóbica", de resistencia social hacia los efectos perversos del turismo (HuETE \& MANTECÓn, 2018; MANSILLA, 2018).

Este contexto es el que constata la necesidad de políticas estratégicas y de una gobernanza de redes en las que los stakeholders implicados colaboren y colideren la gestión del turismo (IVARS-BAIDAL \& al., 2017; CRESPIVallbona \& Mascarilla-MiRó, 2018; Koens \& al., 2018; ECKERT \& al., 2019). Esto es, ciudadanía, administración pública y sector privado deben ser complices y coactores en las acciones a implementar para conciliar los usos de la ciudad con su población tanto permanente como flotante. Una política que asuma objetivos económicos de crecer en la producción, contribuir en el ingreso y la redistribución de esta renta; también objetivos sociales de generar empleo y acceso democrático al ocio; objetivos políticos de generar imagen; y objetivos ambientales de preservar el patrimonio, promoviendo la cultura y propiciando el intercambio entre habitante y visitante. A nivel metropolitanto, el objetivo de la política turística debe plantearse en términos de contribución al desarrollo local y regional, de manera integral, inclusiva, sustentable y sostenible. Precisa crear consciencia colectiva y compartida respecto a los valores e intereses generados, de los imaginarios creados, para redistribuir y descentralizar los flujos de turismo de los espacios centrales turistificados de la metrópolis. La decentralidad territorial de la metrópolis, junto a la connectividad y movilidad dada la estructura nodal de la red y los medios de comunicación y transporte público (viario y ferroviario) facilitan el desarrollo de la "metropolitanización" del turismo (Mantero, 2010). 
El turismo es transversal a la movilidad, a la seguridad, a la vivienda, por lo que su política estratégica no debe ser tratada aisladamente sino estructuralmente en el marco de planes globales. Y otro reto es como convergen los planeamientos urbanísticos que se utilizan para transformar el suelo rústico en urbano -cesión de calles, parques, plazas y equipamientos-, modificando sus derechos -urbanización, edificación y usos públicos y privados- con las actividades económicas de los servicios turísticos -definiciones, regulaciones, restricciones y competencias- capaces de transformar plenamente las ciudades (Font \& al., 2019). No obstante, esta necesidad del turismo de trascender límites territoriales supone problemas legales a la hora de abordar tal fenómeno administrativamente (desde el punto de vista geográfico) y desde un enfoque estratégico meramente sectorial, es decir, solo abordado desde políticas turísticas (FrANKLIN \& CRANG, 2001). En resumen, el turismo manifiesta la necesidad de ser analizado y estructurado estratégicamente desde una dimensión global, tanto geográfica (a nivel de ciudad, regional y nacional), como política (aglutinando los sectores públicos, privados y las organizaciones sociales). Esto es un sistema en red de gobernanza (HALL, 2011; CRESPIVALLBONA, 2021).

\section{Caso de estudio. El Área Metropolitana de Barcelona (AMB)}

\subsection{Objetivos y metodología}

Ante este contexto, nos preguntamos como la actividad turística de Barcelona se expande hacia su área urbana funcional. ¿Representa una real "turistificación"? ¿Se trata de un simple cordón alrededor de la urbe? ¿Se elaboran planes estratégicos pertinentes a tal fenómeno? Ciertamente, el Plan Estratégico de Turismo de la ciudad de Barcelona 2020 (PET20) intenta descongestionar la ciudad y gestionar los flujos de la demanda por todo el territorio, pero ¿contempla los distritos menos turísticos de la ciudad condal o también el AMB? ¿En qué basa la actividad turística el AMB? ¿Cuál es su marca? ¿Existe un Plan estratégico del Turismo en el AMB? En definitiva, puesto que una de las características inherentes del turismo es que sus impactos se desarrollen no solo en el propio destino, sino que se difundan en el entorno inmediato, el objeto de este estudio es analizar la "metropolitanización" del turismo en el AMB (Área Metropolitana de Barcelona), sus características, ritmos, gradaciones, en cuanto a su oferta de vivienda turística, su marca turística y su gobernanza.

Metodológicamente se recurre al análisis de datos secundarios de documentos e informes gubernamentales en torno a la gestión del AMB, esto es del Plan Estratégico Metropolitano de Barcelona (PEMB), del Plan de Turismo Metropolitano (Área Metropolitana de Barcelona, 2017) y del PET20; a datos estadísticos de la demanda y la oferta turística en Barcelona y su AMB; y al análisis de los web promocionales y de producción turística de la Diputació de Barcelona.

\subsection{Contexto geográfico}

El denominado Área Metropolitana de Barcelona (AMB) está configurado por 36 municipios, con una superfície de $636 \mathrm{~km}^{2}$ (FIG. 1) y en el que viven más de 3,2 millones de personas. Constituye una de las áreas metropolitanas más grandes de Europa, con peso significativo en todo el Mediterráneo, y como motor de desarrollo de Cataluña. En 2018, su PIB representó el 51\% del total de Cataluña (Observatori Econòmic Metropolità, 2019), siendo el sector servicios el que lidera el volumen de negocios. No en vano, todas las áreas metropolitanas desempeñan un papel significativo en la economía debido a las redes y flujos productivas y de consumo que se mueven entre los distintos nodos o pools, estableciendo una jerarquia entre estos (VELTZ, 2004)

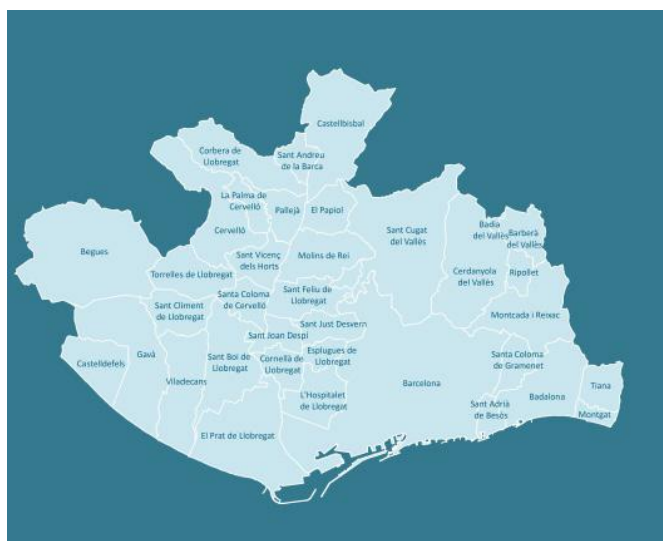

FIG. 1/ Municipios del Área Metropolitana de Barcelona

Fuente: Agència de Desenvolupament Econòmic AMB 
Los Juegos Olímpicos de 1992 impulsan el despego turístico de la ciudad de Barcelona. En 2002, el Año Internacional Gaudí consolida la proyección e imagen internacional, basada en su urbanismo y monumentalidad arquitectónica. Pero, sin duda, es el AMB la corresponsable del desarrollo de Barcelona como destino turístico de primer orden mundial (FIG. 2), primeramente, en la construcción y configuración de la propia metrópolis, pero también en el despliegue de las actividades turísticas: las grandes infraestructuras de transporte (puerto y aeropuerto), la ampliación del recinto ferial y la especialización de la ciudad como hub tecnológico.

Así, el territorio metropolitano, en especial el colindante a la ciudad de Barcelona, ha ejercido de emplazamiento estratégico donde localizar actividades que, por su tamaño y requerimientos, no tenían espacio en la ciudad central y que son resultado de la relevancia y posicionamiento de Barcelona en la red global de destinos turísticos consolidados. Así, como en el caso de las áreas metropolitanas de Asia (RICHARDS, 2010) se constata que son estos territorios la clave del desarrollo del turismo no solo en la metrópolis sino en toda la región.

\subsection{Las políticas turísticas estratégicas de Barcelona y el AMB}

Los planes estratégicos, tanto de la ciudad de Barcelona (Pla Estratègic de Turisme 2020, Ajuntament de Barcelona, 2017) como del AMB (Pla de Turisme Metropolità, AMB, 2017) tienen, entre otros objetivos, fomentar la actividad económica y promover la ocupación y la creación de empresas en los campos de la indústria, el comercio, los servicios y los recursos turísticos. Para el caso de Barcelona, los distintos planes estratégicos que se han sucedido $(1993,2010,2017)$, han procurado posicionar Barcelona económicamente en el marco europeo, consolidarla como destino de atractivo turístico con capacidad de alojamiento y de recursos patrimoniales para su disfrute y conocimiento, y preservar la convivencia ciudadana de los residentes permanentes y los temporales. El tercer plan estratégico de Barcelona pretende situar el AMB en el grupo de las regiones urbanas líderes de la nueva sociedad de la información y del conocimiento del siglo XXI y consolidarse como una de las regiones metropolitanas más importantes de la red europea de ciudades (por la vía de sus especificidades y de su identidad propia).

25.000 .000

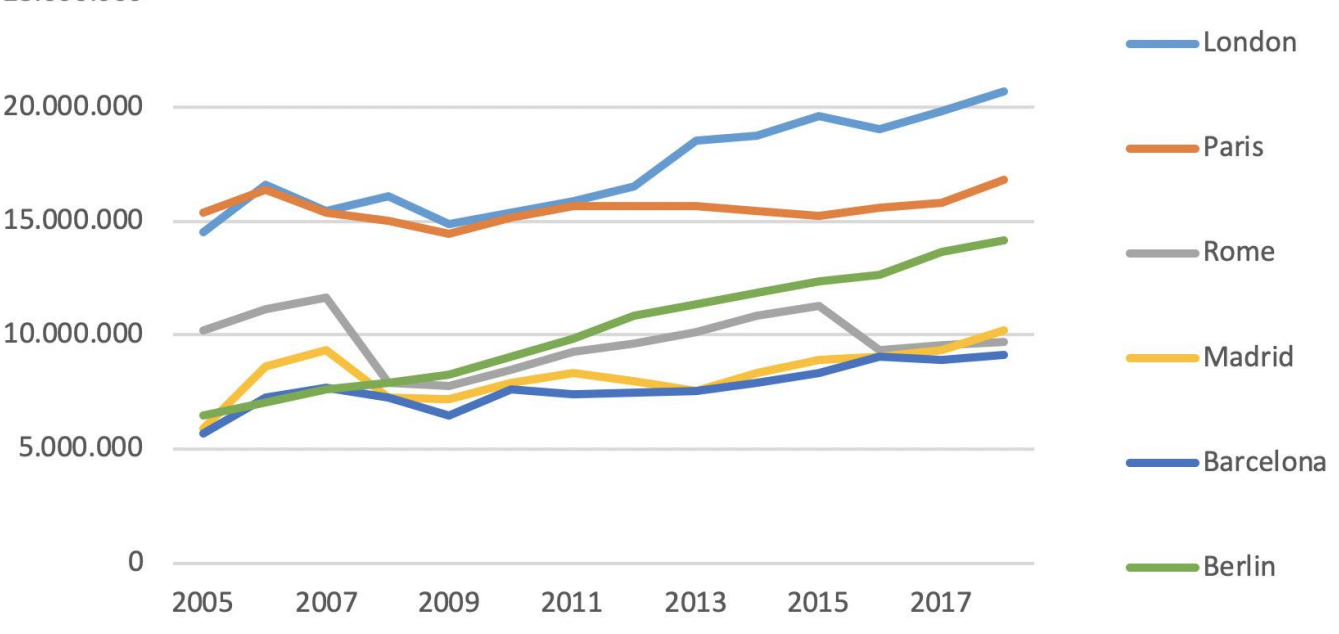

FIG. 2/ Principales ciudades turísticas europeas (2005-2018)

Fuente: Elaboración propia a partir de datos de Euromonitor 
En 2003 se redacta el Primer Plan Estratégico Metropolitano de Barcelona y fomenta que en 2010 se constituya el AMB y se apruebe el Plan Estratégico Metropolitano de Barcelona - Visión 2020, que pretende consolidar el AMB como una de las regiones más atractivas e influyentes para el talento innovador, con un modelo de integración y cohesión social de calidad, siendo sus ejes vertebradores: la universidad y un sistema educativo potente; la administración ágil y fiable, business friendly; y, la gobernanza que potencia la corresponsabilidad público privada en el liderazgo. El esfuerzo del AMB para atraer visitantes se basa en poner en valor su patrimonio cultural y natural, aunque no dispone de pools de atracción turística claramente remarcables. El único recinto con un número de visitantes relevante es en el municipio de Viladecans, The Style Outlet, un shopping center con 2,6 millones de visitas anuales, no necesariamente turistas. Por otro lado, el AMB actúa como elemento puntual de decongestión ante la saturación de la capital, como se percibe durante la celebración del Mobile World Congress, en el que sus asistentes buscan alojamiento, también en las ciudades limítrofes a la ciudad condal. Por tanto, actualmente, el AMB no tiene una estrategia turística propia, pues básicamente depende del impulso y éxito de Barcelona y de su necesidad de desconcentrar y redistribuir los flujos hacia otras áreas.

El Plan de Turismo Metropolitano (AMB, 2017) también afirma que el AMB no dispone de estrategia turística propia, y sus tímidas directrices turísticas se deben a la clara dependencia del área metropolitana de la capacidad atractora y motora de la ciudad de Barcelona. Así mismo, no todos los 36 municipios del AMB disponen de una gestión publica institucionalizada del turismo con concejalías de turismo, planes de turismo, oficinas de turismo, webs promocionales, etc. (López-Palomeque \& Torres-Delgado, 2019). Амат (2016) constata que solamente 6 municipios tienen oficina de información turística. Además, cada municipio clasifica los atractivos en diferentes categorias y nombres (PIÉ \& VILANOVA, 2019), lo que precisa en primer lugar, no solo inventariar los recursos sino unificar los conceptos si se pretende construir un relato único metropolitano.

Todo ello, indica la necesidad de activar estrategias que fortalezcan el liderazgo público en la gobernanza del turismo metropolitano, la creación de un ente público que vele por el desarrollo propiamente turístico y gestione su gobernanza, esto es coordinando las voluntades de las diferentes administraciones locales de los 36 municipios. Un ente que no solo debe coordinar la "metropolitanización" del turismo, sino crear imagen, relato, crear vocación turística. Además, debe contabilizar su oferta y su demanda. Actualmente, los datos que se manejan de la actividad turística del AMB son muy escasos, puntuales y sin continuidad en el tiempo.

\subsection{Turistificación en el AMB}

El AMB está irradiado desde el punto de vista turístico por el éxito de la marca Barcelona y sus iconos de atracción internacional (LóPEzPalomeque \& Torres-Delgado, 2019). En este sentido, el AMB no dispone de una oferta turística articulada, sino que responde puntualmente cuando la capacidad de carga de Barcelona se ve sobrepasada. Su demanda, se debe al interés que genera la ciudad de Barcelona, a criterios de accesibilidad, distancia, precio y oportunidad. Pero es puntual, muy circunstancial.

El caso más remarcable es el de Hospitalet de Llobregat, cuyo municipio alberga las nuevas instalaciones para el turismo MICE (Meetings, Incentives, Conferences and Exhibitions) de Fira Gran Via (inaugurado en 2011) lo que ha repercutido en el desarrollo de un núcleo hotelero en sus alrededores. Otros municipios, como Castelldefels, Gavà, Corbera o Begues han tenido siempre vocación turística, con numerosas viviendas de segunda residencia. De hecho, son localidades turísticas que nacen como segundas residencias de veraneo para las clases acomodadas en el primer tercio del siglo XX (PIÉ \& VILANOVA, 2019). En este contexto, destaca el incremento del alojamiento reglado, tanto hotelero como de viviendas de uso turístico (VUT) (FIG. 3). No obstante, se constata que manifiestamente el número de plazas de VUT no ha hecho más que aumentar en el AMB y en el caso de Barcelona ciudad han ido disminuyendo, debido al efecto centrífugo que ha tenido la regulación del alojamiento en Barcelona ciudad hacia su entorno metropolitano más cercano. Se trata de la moratoria de licencias de 2014 para viviendas de uso turístico (Habitatges d'Ús Turístic (HUT)) y del Plan Especial Urbanístico de Alojamiento Turístico (PEUAT, 2017). 
를 Barcelona 를 $\mathrm{AMB}(\mathrm{Sin} \mathrm{BCN})$

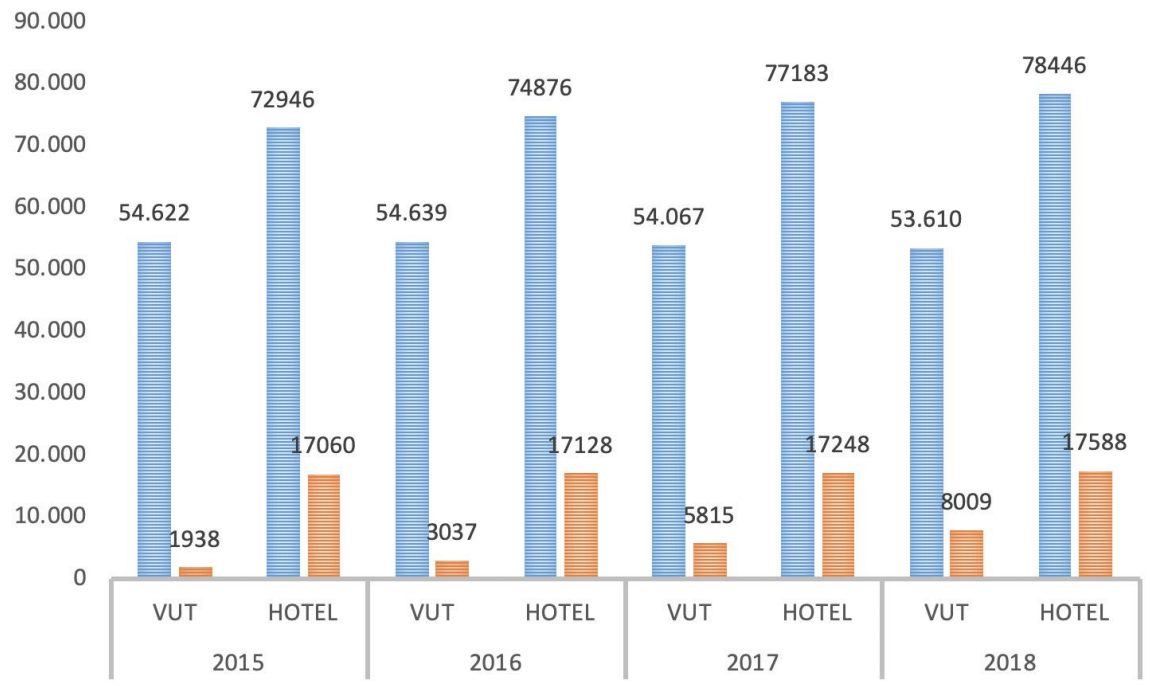

FIG. 3/ Evolución de la oferta de alojamiento turístico en el AMB (2015-18)

Fuente: Elaboración propia a partir de los datos del Institut d'Estudis Metropolitans de Barcelona

En la FIG. 4, se observa como son los municipios colindantes con Barcelona, los que más notoriamente han incrementado su volumen de plazas de alojamiento de viviendas de uso turístico reglado. Especialmente, Hospitalet de Llobregat, Sant Adrià del Besòs, Santa Coloma de Gramanet y Sant Cugat del Vallès.

EL PEUAT cubre el término municipal de Barcelona, estableciendo las condiciones de regulación para los alojamientos turísticos, delimitando zonas de decrecimiento, mantenimiento y de crecimiento contenido en función de indicadores como el grado de concentración de establecimientos turísticos, la población flotante versus residente, la presión sobre los espacios públicos, y los barrios saturados y sensibilizados turísticamente. La limitación de nuevas licencias en la ciudad de Barcelona desde 2014 ha provocado un aumento de la demanda de estas actividades en

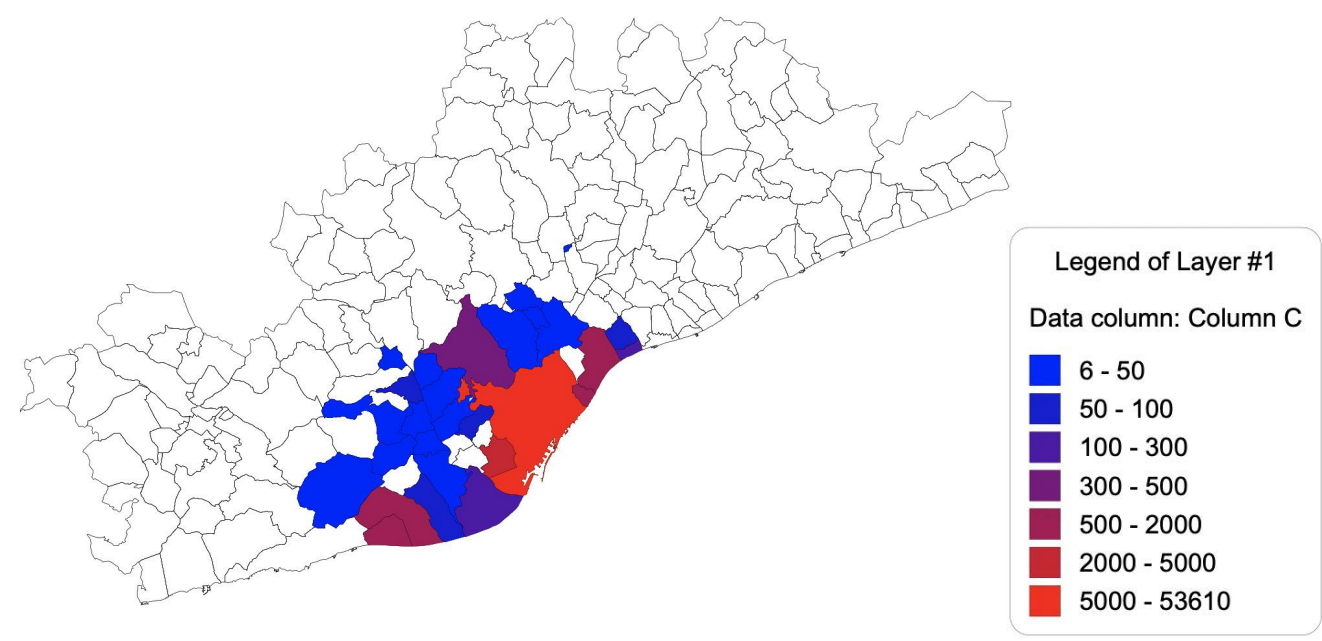

FIG. 4/ Intensidad de la oferta de alojamiento VUT en el AMB (2018)

Fuente: Elaboración propia a partir de los datos del Institut d'Estudis Metropolitans de Barcelona 
los municipios metropolitanos, tanto de actividad legal, como seguramente de la ilegal en las plataformas comercializadoras del alojamiento horizontal o colaborativo, como AirBnb, Homeaway y otras. Específicamente, destaca el incremento de plazas regladas en los municipios de Hospitalet de Llobregat (2558 plazas); Castelldefels (1914 plazas); Gavà (1034 plazas), Badalona (501), Sant Adrià (539), Sant Cugat (330), Cornellá del Llobregat (198) y Esplugues de Llobregat (88), según los datos del Institut d'Estudis Regionals i Metropolitans de Barcelona (2019). Se observa que el PEUAT es, en definitiva, un plan preventivo, más que correctivo o redistributivo (FONT \& al., 2019), puesto que, como se observa las acciones de presión e inspección ante los pisos turísticos ilegales de las plataformas de alojamiento horizontal, tiene un efecto expansión a los municipios limítrofes, atentos a tales posibilidades y ajenos a tales restricciones. Cabe señalar que, a día de hoy, el PEUAT ha sido recurrido en los tribunales y está a la espera de su resolución final. En cualquier caso, el gobierno local tiene el compromiso de revisar su contenido y actuación.

\subsection{Los atractivos turísticos en el AMB}

La marca Barcelona invade el panorama turístico y no deja opción al AMB. A pesar de que la Sociedad de Atracción de Forasteros (primer ente promotor de turismo de la ciudad de Barcelona) en las primeras décadas del siglo $X X$ ya puso en valor el entorno natural y el patrimonio industrial de las poblaciones vecinas de Barcelona e invitaba a los forasteros a visitarlas (PALOU, 2019), la marca, imagen y relato de Barcelona se ciñen al límite municipal. Tampoco parece que por ahora exista una capacidad técnica del AMB para atraer turistas, puesto que no se ha conseguido crear imagen o apego al AMB. Hay tímidos intentos desde la Diputación de Barcelona por crear "Destino Barcelona" con la campaña "Barcelona és molt més", con el objetivo de diluir la capacidad atractiva de la ciudad de Barcelona e incorporar el resto de la provincia. Tímidos intentos, con igualmente tímidos resultados. El número de turistas que pernoctan en Barcelona es muy superior al que pernoctan en el resto de la provincia de Barcelona y en la Comunidad Autónoma de Cataluña (FIG. 5). Se compara territorialmente con la comunidad autónoma y la provincia puesto que no se dispone de datos específicos del turismo que recibe el AMB.

Los efectos económicos positivos del turismo son contrarrestados por sus impactos negativos. En este sentido, tal y como se observa en la FIG. 6 , la ciudadanía de la capital barcelonesa si bien consideran que la actividad turística beneficia económicamente la ciudad por lo que apoyan que continúe atrayendo visitantes, cada vez hay más ciudadanos descontentos con la saturación de esta población flotante que invade y congestiona los espacios urbanos. Y más todavía, si

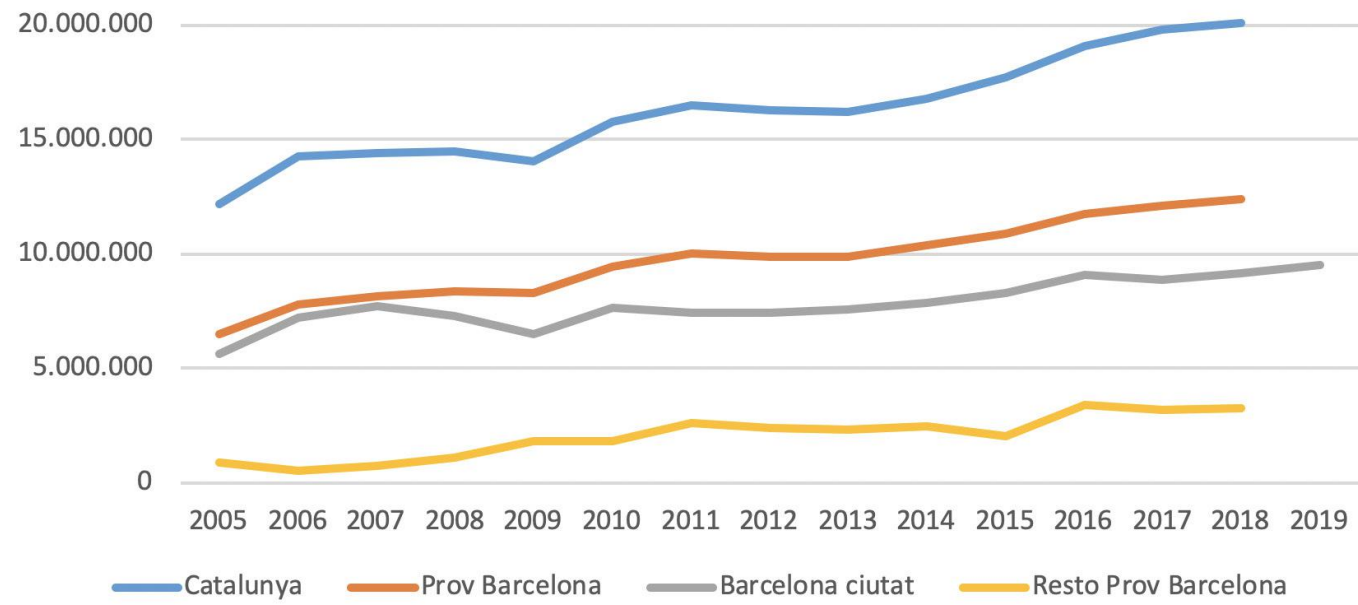

FIG. 5/ Evolución del turismo en Cataluña y Barcelona: provincia y ciudad (2005-2019) 


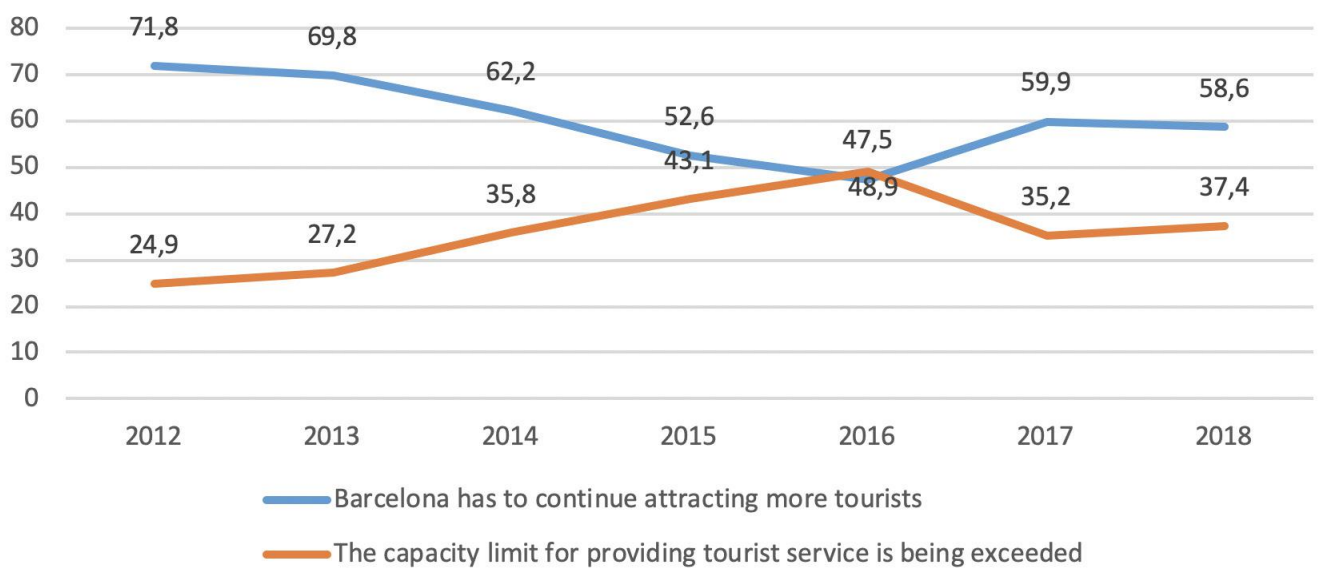

FIG. 6/ Evolución del soporte/rechazo al turismo de las personas residentes en Barcelona (2012-2018)

Fuente: Elaboración propia a partir de datos de Turisme de Barcelona.

todo ello ha llevado a los vecinos a movilizarse y expresar sus reticencias y resistencias ante tal desapego económico, social y cultural, en el que el auge del turismo ha tenido tanto que ver.

Un momento conflictivo decisivo fue en el primer semestre del año 2016, cuando en el barómetro municipal (FIG. 7), los ciudadanos manifestaron su desafección hacia el turismo, a raíz del cual, la administración local tomó medidas en sus planes estratégicos. Actualmente, las principales preocupaciones de la ciudadanía de Barcelona se centran en la inseguridad $(17,1 \%)$, el paro y las condiciones laborales $(17,1 \%)$ y el acceso a la vivienda (12,2\%). El turismo tuvo su auge de rechazo en el 2017 (15,6\%), pero actualmente se ha rebajado notablemente la intensidad de su desafección $(5,2 \%)$.

Barcelona es pues una metrópolis turística que convive con sus bonanzas y sus frustaciones. Así mismo, resulta contradictorio constatar la satisfacción y apego que tienen los barceloneses y las barcelonesas por su ciudad (FIG. 8), en la que su

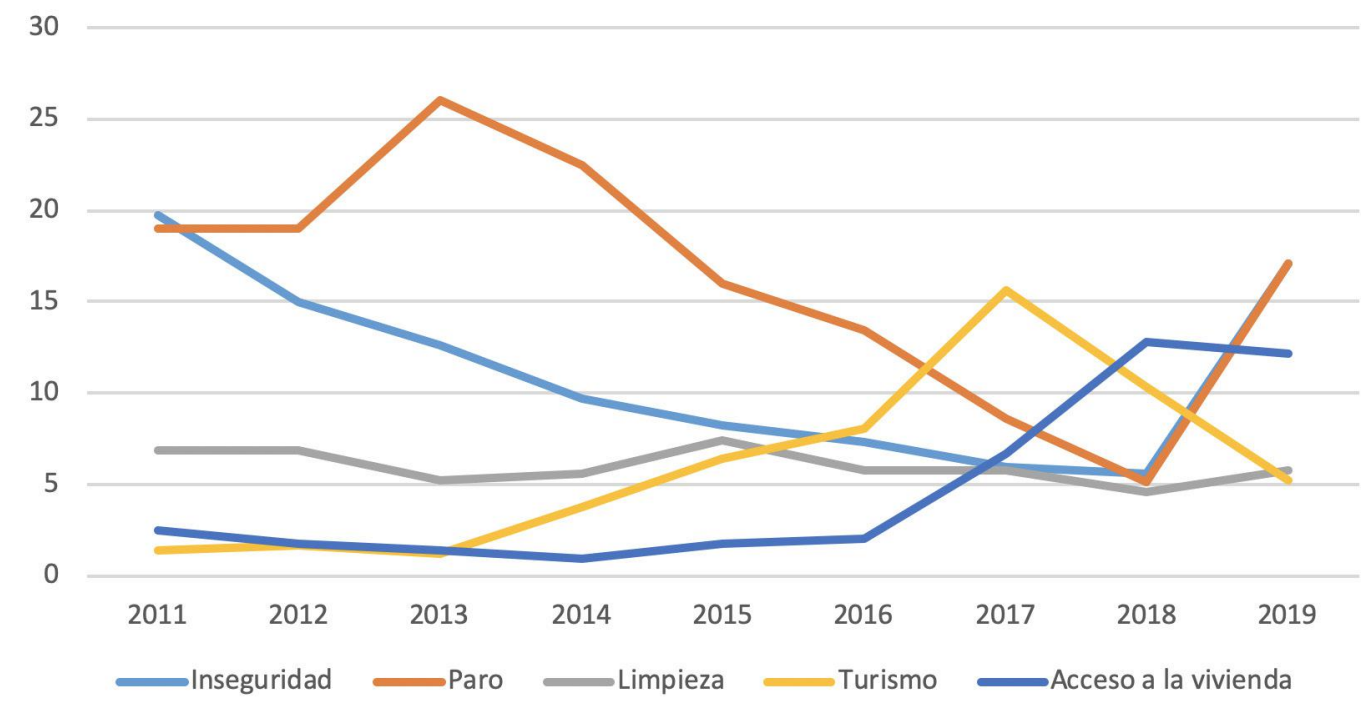

FIG. 7 / Evolución de las preocupaciones de la ciudadanía de Barcelona (2011-19)

Fuente: Elaboración propia a partir de datos de la Encuesta Turisme de Barcelona. 


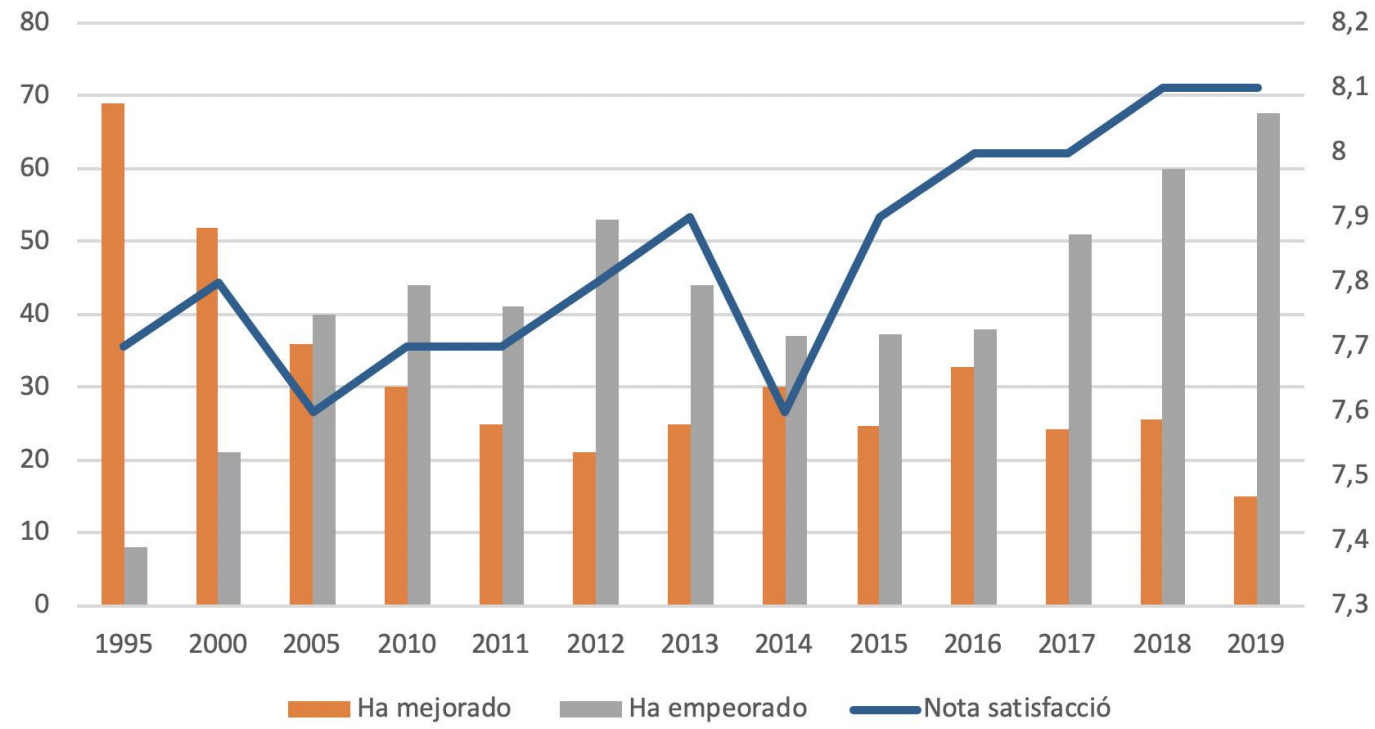

nota oscila en el 8, a pesar que consideran que su ciudad ha empeorado notablemente desde 2005. Por ello, son un tanto curiosos estos datos, pues confieren una sensación de que aunque la ciudad no presenta aspectos del todo positivos, su ciudadanía considera que la imagen que proyecta es satisfactoria. O precisamente, este apego a su comunidad, esa identificación con su ciudad les lleva a este recelo manifiesto.

No obstante, lo que resulta difícil es crear un imaginario, un relato, un sentimiento de apego, de pertenencia al $A M B$, que es lo que primero se necesita para posicionar una marca en el mercado, y generar una posterior afección a ésta (y consecuentemente también el apoyo y/o rechazo a la actividad turística).

La tematización sería uno de los instrumentos a utilizar, puesto que no hay atractivos suficientemente imponentes en el AMB para atraer visitantes, principalmente internacionales. Una tematización generada a partir y desde Barcelona complementada con el AMB. Esto es, compartir las sinergias entre iconos emblemáticos de la ciudad de Barcelona y del resto de su área funcional. Un claro ejemplo es Gaudí. El potencial atractivo del modernismo y Gaudí es innegable y es una de las bases en las que se sustenta el éxito de Barcelona. Las visitas del Park Güell, la Pedrera, el Palau Güell y la Sagrada Família en la ciudad, se podrían completar con la experiencia y el descubrimiento de la Colonia Güell en Santa Coloma de Cervelló. Un carnet cultural que facilitara la visita de todos los monumentos gaudinianos sería una herramienta de promoción sensata.

También lo sería el binomio Poble Espanyol y Catalunya en Miniatura en Torrelles de Llobregat, dos museos etnográficos al aire libre que constatan la idiosincrasia arquitectónica de los pueblos catalán y español. Las distintas titularidades de los monumentos y museos serían el primer obstáculo a salvar.

No obstante, ante la necesidad de una marca unificada para todo el territorio AMB, seguramente se podría recuperar el pasado fabril de la ciudad y los municipios del AMB, olvidado por los promotores de turismo de Barcelona según CAPEL (2005), para construir un relato unitario de todo el territorio en torno al patrimonio industrial. $\mathrm{O}$, atendiendo al despunte del street art en los barrios barceloneses del Raval (RIus-UlLdemolins, 2018), Poble Nou (KLEIN, 2018), Sants y Les Corts (CRespi-Vallbona \& Mascarilla-Miró, 2020) y en la localidad de Hospitalet de Llobregat, se podría impulsar una ruta para descubrir las distintas concepciones, utilidades y formas 
del arte urbano. Se trata de un paisaje visual, cotidiano y mundano, pero también estetizado, resignificado y embellecido que invita al paseo. No debemos olvidar que los turistas son amantes de los espacios peatonalizados (JIMÉNEZ \& al., 2019) para el disfrute de sus sentidos (URRY, 1990).

\section{Conclusiones}

El objectivo de este articulo es aunar en la "turistificación" del área urbana funcional de una urbe consolidada turísticamente; esto es, profundizar en el turismo metropolitano implementado en el AMB, especialmente en el alojamiento horizontal de viviendas turísticas, la marca turística comercializada y la gobernanza desempeñada.

Se constata que la "metropolitanización" del turismo en el AMB es residual. A día de hoy, actúa como elemento puntual de descongestión ante la saturación de la capital, principalmente durante eventos como el Mobile World Congress. Pero no tiene relato ni identidad capaz de atraer a los visitantes internacionales que llegan a Barcelona. Es necesario activar estrategias que fortalezcan el liderazgo público en la gobernanza del turismo metropolitano, tanto de creación de marca, como de colección de datos y estadísticas, como de regulación estratégica. La planificación turística metropolitana debe garantizar la cohesión y participación de todos los agentes involucrados, tejiendo redes y complicidades. A día de hoy, existen demasiados entes administrativos trabajando local y supralocalmente, focalizándose en su territorialidad y sin unir esfuerzos. La constitución de un ente encargado de la gestión única del turismo en el AMB visibilizaría su estrategia.

En cuanto a la oferta de vivienda de uso turístico, se observa un aumento de este alojamiento en el $\mathrm{AMB}$, en detrimento de Barcelona, debido al efecto centrífugo del PEUAT, principalmente en los municipios colindantes con la ciudad condal (Hospitalet de Llobregat y Sant Adrià del Besós) y los muncipios de tradicional turismo de segundas residencias (Castelldefels o Gavá).

Por otro lado, los intentos del PET20 de redistribución del flujo turístico son imperceptibles, puesto que no existe relato turístico. Barcelona solo ubica infraestructuras fuera de sus límites geográficos debido a su falta de espacio físico. La creación de productos temáticos podría ser un inicio para el turismo metropolitano. Las sinergias de los recursos gaudinianos podrían ser objeto de una ruta temática. El street art podría convertirse en otro paisaje visual para recórrer a pie (o en automóvil) en todo el territorio del AMB. Se construiría de esta forma una agenda cultural y social tanto para los residentes del territorio metropolitano, para que estos puedan vivir en su espacio municipal, como turistas, como reclamo para los visitantes internacionales (HARVEY, 1989).

En definitiva, el AMB será turística en el momento que sea atractiva como territorio para descubrir, con imágenes creadas y proyectadas, principalmente para la alteridad; pero también con espacios cotidianos que persistan. Cuando cree su propia marca, su propio relato, a tenor de su pasado fabril o en el momento que suscite glamour por los paisajes de street art. En el momento actual, sigue manteniendo el rol de colofón de la magnánime marca Barcelona.

\section{Bibliografía}

Амat, E. (2016): "Recopilació de la Informació, Estratègies i Iniciatives sobre el Turisme als ens locals de l'àmbit de l'Àrea Metropolitana de Barcelona". En Pié, R. \& J.M. Vilanova (Eds.), Estudi Usos Urbanístic i el Turisme en el PDU-AMB. (57-87), Barcelona: Area Metropolitana de Barcelona.

Antich, X. (2013): La ciutat del disseny. Barcelona: Centre de Cultura Contemporània de Barcelona.

Antón Clavé, S. (1998): La urbanización turística: de la conquista del viaje a la reestructuración de la ciudad turística. Documents d'Anàlisi Geogràfica, 32, 17-43.

Arias SANS, A. (2018): Turisme i gentrificació: apunts des de Barcelona. Papers. Regió Metropolitana de Barcelona, 60, 130-139.

-------(2019): Turisme i metròpoli. Apunts per a una agenda integrada. Papers, 62, 10-19

BAPTISTA, L. (2005): Territórios lúdicos (e o que torna lúdico um território): Ensaiando um ponto de partida, Fórum Sociológico, 13/14, 47-58.

BarRado, D. (2010): Gran ciudad y turismo en la transición postindustrial: nuevos y viejos procesos, nuevas y viejas teorías. El caso del área metropolitana de Madrid. Scripta Nova. Revista electrónica de Geografía y Ciencias Sociales, 14 (317). http://www.ub.edu/geocrit/sn/ sn-317.htm.

BAssand, M. \& Joye, D. (2001): Vivre et créer l'espace public. Lausanne: PPUR presses polytechniques.

Bertoncello, R. (2002): Turismo y territorio. Otras miradas. Aportes y Transferencias, 6 (2), 31-50

------\& Castro, H., \& Zusman, P. (2003): "Turismo y patrimonio: una relación puesta en cuestión". En 
Bertoncello, R., Carlos, A. F. (Eds). Procesos Territoriales en Argentina y Brasil, (277-291), Buenos Aires: Instituto de Geografía.

------ \& Luso, R. (2016): Turismo urbano en contexto metropolitano: Tigre como destino turístico en el Área Metropolitana de Buenos Aires (Argentina). Cuadernos de Geografía: Revista Colombiana de Geografía, 25 (2), 107-125.

BEst, G. (2012): "In the eye of the beholder: Street art, landscape, and the tourist gaze refocused", 60-65. In CAUTHE: The new golden age of tourism and hospitality; Book 2; Proceedings of the 22nd Annual Conference

Boyer, M. C. (2004): "Ciudades en venta: la comercialización de la historia en el South Street Seaport". En Sorkin, M. (Ed): Variaciones sobre un parque temático: la nueva ciudad americana y el fin del espacio público, (205-230), Barcelona: Gustavo Gili.

BRIDGE, G., \& Dowling, R. (2001): Microgeographies of retailing and gentrification. Australian Geographer, 32 (1), 93-107.

ButLER, R.W. (1980): The concept of a tourist area cycle of evolution: implications for management of resources. Canadian Geographer, 24, 5-12

Capel, H. (2005): Modelo Barcelona: un examen crítico. Barcelona: Ediciones del Serbal.

Chaudefaud, M. (1987): Aux origines du tourisme dans les Pays de l'Adour: du mythe à l'espace: un essai de géographie historique. Pau: Département de géographie et d'aménangement de l'Université de Pau et des Pays de l'Adour, Centre de recherche sur l'impact socio-spatial de l'aménagement

ChoAy, F. (2000): A alegoria do património. Lisboa: Edições 70

Cócola-Gant, A (2018): "Tourism gentrification", 281-293 en A L. Lees, y M. Phillips (Eds.), Handbook of Gentrification Studies. Cheltenham and Northampton: Edward Elgar Publishing.

Cohen, E. (2005): Principales tendencias en el turismo contemporáneo. Política y sociedad, 42(1), 11-24.

Colomb, C. \& Novy, J. (eds.) (2016): Protest and resistance in the tourist city. Nueva York: Routledge.

CRANG, M. (1999): "Knowing, Tourism and Practices of Vision". En Crouch, D. (ed): Leisure/tourism geographies: Practices and geographical knowledge, (238-256), London: Routledge.

Crespi-Vallbona, M. (2021): Gobernanza sostenible en espacios públicos. Cuadernos de Geografía: Revista Colombiana de Geografía, en prensa

------\& DIMITRovskı, D. (2016): Food markets visitors: a typology proposal. British Food Journal, 118 (4), 840-857

-------\& Domínguez-PÉrez, M. (2021): Las consecuencias de la turistificación en el centro de las grandes ciudades. Ciudad y Territorio Estudios Territoriales (CyTET), 61-82. https://doi. org/10.37230/

\& MAscarilla Miró, O. (2018): La transformación y gentrificación turística del espacio urbano. El caso de la Barceloneta (Barcelona). Eure, Revista Latinoamericana de Estudios Urbano Regionales. 133 (44), 165-184.
\& Mascarilla Miró, O. (2020): Street Art as a Sustainable Tool in Mature Tourism Destinations: The Case Study of Barcelona. International Journal of Cultural Policy, https://doi.org/10.108 0/10286632.2020.1792890.

DeLGADO, M. (2004): "La cultura dels carrers. L'espai públic com a patrimoni sociocultural". En Soldino, E. \& al. (ed), Patrimoni i societat: conservació $i$ gestió del patrimoni cultural, (61-77), València: Publicacions de la Universitat de València

Delgado Ruiz, M. (1999): Ciudad líquida, ciudad interrumpida. La urbs contra la polis. Medellín: Colección Estética Expandida, Editorial Universidad de Antioquia.

Dominguez-Pérez, M., Leal-Maldonado, J., \& Barañano-Cid, M. (2021): Vivienda, transformaciones urbanas y desigualdad socioespacial en las grandes ciudades españolas. Ciudad y Territorio Estudios Territoriales (CyTET), 5-12. https://doi.org/10.37230/CyTET.2021.M21.00

DunCAN, J.S. \& DunCAN, N. (2001): The Aestheticization of the Politics of Landscape Preservation. Annals of the Association of American Geographers, 91 (2), 387-409.

ECKERT, C.\& al. (2019): Strategies and measures directed towards overtourism: a perspective of European DMOs. International Journal of Tourism Cities. https://doi.org/10.1108/IJTC-12-2018-0102

ERNSt, O., \& Doucet, B. (2014): A window on the (changing) neighbourhood: The role of pubs in the contested spaces of gentrification. Tijdschrift voor economische en sociale geografie, 105(2), 189-205.

Feria ToRIBIo, J. M. (2004): Problemas de definición de las áreas metropolitanas en España. Boletín de la Asociación de Geógrafos Españoles, (38), 85-100.

Font, T., López, A. \& Clot, R. (2019): El Pla Especial Urbanístic d'Allotjaments Turístics (PEUAT). Una eina contingent per regular el turisme, Papers, 62, 70-77

Franklin, A. \& CRang, M. (2001): The trouble with tourism and travel theory? Tourist Studies, 1, 5-22.

FrIsch, T. \& al. (Eds.): Tourism and everyday life in the contemporary city. Abingdon, Oxon; New York, Routledge.

FülleR, H., \& MıCHEL, B. (2014): 'Stop Being a Tourist!' New Dynamics of Urban Tourism in BerlinKreuzberg. International Journal of Urban and Regional Research, 38 (4), 1304-1318.

Galofaro, L. (2003): Paisajes en transformación" Artscapes. El arte como aproximación al paisaje contemporáneo. Barcelona, Gustavo Gili.

Goldstone, P. (2003): Turismo. Más allá del ocio y del negocio. Madrid: Debate.

GonzÁlez, S. \& WALEY. P. (2012): Traditional Retail Markets: The New Gentrification Frontier, Antipode, 45 (4), 965-983

Gotнам, K. F. (2002): Marketing Mardi Gras: Commodification, spectacle and the political economy of tourism in New Orleans. Urban Studies, 39 (10), 1735-1756.

Gravari-Barbasa, M., Jacquot, S. \& Cominelli, F (2017): New cultures of urban tourism. 
International Journal of Tourism Cities, 5 (3), 301-306.

Greenwood, D. (1972): Tourism as an Agent of Change: A Basque Case, Ethnology, 11(1), 80 $-91$.

Gupta, A. \& Ferguson, J. (1992): Beyond "Culture": Space, identity and the Politics of difference. Cultural Anthropology, 7 (1), 6-23.

HALL, C. M. (2011): A typology of governance and its implication for tourism policy analysis. Journal of Sustainable Tourism,19 (4/5), 437-457.

Hannerz, U. (1989): Culture between Center and Periphery: Toward a Macroanthropology. Ethnos, 54 (3-4), 200-16

HARVEY, D. (1989): The Condition of Postmodernity. An Enquiry into the Origins of Cultural Change. EEUU: Basil Blackwell.

------(2002): "The art of rent: globalization, monopoly and the commodification of culture". En: Panitch, I. \& C. Leys (eds.): A World of Contradictions. Socialist Register.

Huete, R., \& MANTECón, A. (2018): El auge de la turismofobia ¿hipótesis de investigación o ruido ideológico?. Pasos, 16 (1), 9-19

IVARS-BAIDAL, J. A. \& al. (2017): Smart destinations and the evolution of ICTs: a new scenario for destination management? Current Issues in Tourism, 1581-1600

Jansen-Verbeke, M. (1998): Touristification of historical cities: a methodological exercise. Annals of Tourism Research, 25 (3), 739-742.

JiMÉnEZ, C \& al. (2019): La integració de la demanda turística en la planificació i la gestió de la mobilitat. Apunts des de la destinació Barcelona. Papers, 62, 120-132.

KLEIN, R. (2018): La ciudad y el turismo: Experiencias desde la gestión del street art. Sociologia, (8), 54-71.

Koens, K., Postma, A. \& Papp, B. (2018): Is overtourism overused? Understanding the impact of tourism in a city context. Sustainability, 10 (12), 4384.

Lazzarotti, O. (1994): La géographie dans la controverse touristique. Annales de Géographie, 103 (580), 627-650

LÓPEZ LÓPEZ, J. (2016): El patrimonio como constructo político y su potencial reflexivo. Perspectivas, Revista del PH Instituto Andaluz de Patrimonio Histórico, 90, 218-219.

López Palomeque, F. (2015): Barcelona, de ciudad con turismo a ciudad turística. Notas sobre un proceso complejo e inacabado. Documents d'anàlisi geogràfica, 61(3), 483-506.

------\& Torres-Delgado, A. (2019): El turisme a l'Àrea Metropolitana de Barcelona, Papers, 62, 20-35

LübBren, N. \& CRouch, D. (2003): Visual culture and tourism. Berg Publishers.

MacCAnnelL, D. (2003): [1976]. El Turista: una nueva teoría de la clase ociosa. Barcelona: Melusin.

Maitland, R. \& Newman, P. (2009): "Developing world tourism cities", 1-21. In Maitland, R. \& Newman, $\mathrm{P}$ (Eds): World tourism cities: Developing tourism off the beaten track. London: Routledge.

MANSILLA, J.A. (2018): Vecinos en peligro de extinción. Turismo urbano, movimientos sociales y exclusión socioespacial en Barcelona. Pasos. Revista de Turismo y Patrimonio Cultural, 16 (2), 279-296.
Mantero, J. C. (2010): Turismo metropolitano: la potencia de lo urbano. Aportes $y$ Transferencias, 14(2), 121-144.

Milano, C. (2018): Overtourism, malestar social y turismofobia. Un debate controvertido. Pasos, 16 (3), 551-564

MILES, M. (2007): Cities and Cultures. Londres: Routledge.

Mıossec, J. M. (1977): Un modèle de l'espace touristique. L'Espace géographique, 41-48.

Mitchell, D. (2003): Cultural landscapes: just landscapes or landscapes of justices? Progress in Human Geography, 27 (6): 787-796.

Mordue, T. (2017): New urban tourism and new urban citizenship: researching the creation and management of postmodern urban public space. International Journal of Tourism Cities, 6 (4), 399-405.

Palou Rubio, S. (2019): Discursos turístics sobre el paisatge i el patrimoni cultural de Barcelona. Imatges contra la ciutat, Papers, 62, 48-58

PeEters, P. \& al. (2018): Research for TRAN Committee-Overtourism: impact and possible policy responses.

PiÉ, R. \& Vilanova, J.M. (2019): Els reptes del planejament urbanístic metropolità enfront el turisme, Papers, 62, 60-68

Prats, L. (2004): Antropología y patrimonio. Barcelona: Ariel

----(2009): "Turismo e identidad: un intercambio narrativo". En Fernández Cerviño, M.X. (Ed.), Turismo e identidade. (42-50), Santiago de Compostela: Museo do Pobo Galego.

Richards, G. (2010): Metropolitan Tourism: Competition, Collaboration and Creativity. Asia Pacific World, 1(1): 75-94

------(2016): El turismo y la ciudad ¿Hacia nuevos modelos? Revista Cidob d'afers internacionals, 113, 71-87.

Rius-Ulldemolins, J. (2008): Los barrios artísticos como base local de la cultura global. El caso del Raval de Barcelona. Revista Internacional de Sociología, LXVI (51), 179-205

Rubio-Ardanz, J.A. (2014): Antropología y Maritimidad. Entramados y constructos patrimoniales en el Abra y Ría de Bilbao. Bilbao: Museo Marítimo Ría de Bilbao

SAARINEN, J. (2006): Traditions of sustainability in tourism studies. Annals of Tourism Research, 33 (4), 1121-1140.

SalazAR, N. B. (2005): Tourism and glocalization "local" tour guiding. Annals of tourism research, 32(3), 628-646.

SASSEN, S. (2014): Expulsions: Brutality and complexity in the global economy. Harvard University Press.

Sengel, T. \& al. (2015): Tourists' approach to local food. Procedia-Social and Behavioral Sciences, 195(1), 429-437.

Sheller, M. \& URRY, J. (2004): Tourism mobilities: Places to play, places in play. Londres: Routledge.

Silver, D. A. \& Clark, T. N. (2016): Scenescapes: How qualities of place shape social life. Chicago: University of Chicago Press.

Stebbins, R. A. (1997): Identity and cultural tourism. Annals of tourism research, 24(2), 450-452. 
Estudios

Stors, N. \& KagermeiJer, A. (2013): "Crossing the border of the tourist bubble: touristification in Copenhagen". En Thimm, T. (Ed). Tourismus und Grenzen. (115-131), Manheim: MetaGis.

UNWTO, (2018), Overtourism? Understanding and Managing Urban Tourism Growth beyond Perceptions. Executive Summary, Madrid: UNWTO (OMT)

URRY, J. (1990): The Tourist Gaze: Leisure and Travel in Contemporary Societies. London: Sage Publications

Veltz, P. (2004): The Resurgent City. Leverhulme International Symposium, London School of Economics, 19-21 April.

ZukIN, S. (1995): The Cultures of Cities. London: Blackwell.
(2008): Consuming authenticity: From outposts of difference to means of exclusion. Cultural studies, 22(5), 724-748.

\section{Listado de acrónimos/siglas}

AMB: Área Metropolitana de Barcelona

PET20: Plan Estratégico de Turismo de la ciudad de Barcelona 2020

PEUAT: Plan Especial Urbanístico de Alojamiento Turístico

UNWTO: Organización Mundial del Turismo OMT

VUT: Viviendas de Uso Turístico 